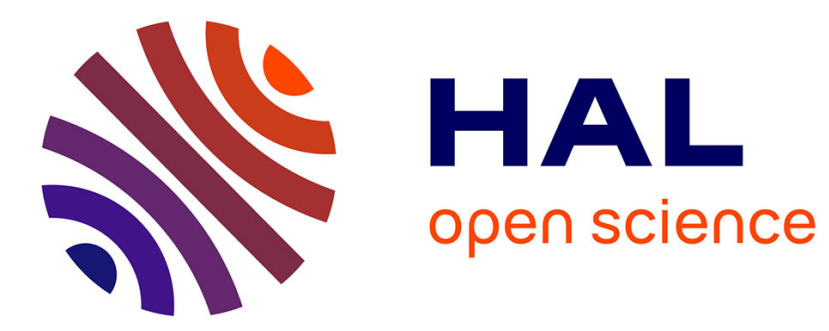

\title{
Role of dynamin 2 in the disassembly of focal adhesions
} Laura Briñas, Stéphane Vassilopoulos, Gisele Bonne, Pascale Guicheney, Marc

Bitoun

\section{To cite this version:}

Laura Briñas, Stéphane Vassilopoulos, Gisele Bonne, Pascale Guicheney, Marc Bitoun. Role of dynamin 2 in the disassembly of focal adhesions. Journal of Molecular Medicine, 2013, 91 (7), pp.803-809. 10.1007/s00109-013-1040-2 . hal-02453840

\section{HAL Id: hal-02453840 \\ https://hal.science/hal-02453840}

Submitted on 24 Jan 2020

HAL is a multi-disciplinary open access archive for the deposit and dissemination of scientific research documents, whether they are published or not. The documents may come from teaching and research institutions in France or abroad, or from public or private research centers.
L'archive ouverte pluridisciplinaire HAL, est destinée au dépôt et à la diffusion de documents scientifiques de niveau recherche, publiés ou non, émanant des établissements d'enseignement et de recherche français ou étrangers, des laboratoires publics ou privés. 


\section{Role of dynamin 2 in the disassembly of focal adhesions}

Laura Briñas ${ }^{1,2,3,4}$, Stéphane Vassilopoulos ${ }^{1,2,3,4}$, Gisèle Bonne $e^{1,2,3,4,5}$, Pascale Guicheney ${ }^{6}$, Marc Bitoun ${ }^{1,2,3,4}$.

1. Université Pierre et Marie Curie-Paris 6, UM76, Paris, F-75013, France.

2. Inserm, U974, Paris, F-75013, France.

3. CNRS, UMR 7215, Paris, France.

4. Institut de Myologie, Paris, France.

5. AP-HP, Groupe Hospitalier Pitié-Salpêtrière, U.F. Cardiogénétique et Myogénétique, Service de Biochimie Métabolique, Paris, F-75013, France.

6. Inserm, U956, Paris, F-75013, France.

\section{Corresponding Author:}

Marc Bitoun, Inserm U974, Institut de Myologie, Paris, France.

E-mail: m.bitoun@institut-myologie.org

Tel: $33(0)$ 1.42.16.57.18.

Fax: 33 (0) 1.42.16.57.00. 


\begin{abstract}
Dynamin 2 (DNM2) is involved in endocytosis and intracellular membrane trafficking through its function in vesicle formation from distinct membrane compartments. During the last decade, several studies pointed out an important role of DNM2-dependent trafficking in turnover of focal adhesions which represent a physical link between the extracellular matrix and the intracellular actin cytoskeleton, and a platform for several signaling pathways. Here, we review the involvement of DNM2 in structural and functional aspects of the focal adhesion sites. Mutations in the DNM2 gene cause two hereditary neuromuscular disorders; dominant centronuclear myopathy and Charcot-Marie-Tooth peripheral neuropathy. Potential impairment of focal adhesions as a pathophysiological hypothesis in DNM2-related human diseases is discussed.
\end{abstract}

\title{
Keywords:
}

Dynamin 2, Focal adhesion, endocytosis, focal adhesion disassembly 
Dynamin 2 (DNM2) is a ubiquitously expressed large GTPase, involved in various membrane trafficking events. At the plasma membrane, DNM2 is involved in the formation and release of vesicles for the clathrin-mediated [1] and clathrin-independent endocytosis [2, 3]. DNM2 also participates in the formation of transport vesicles from the endosomal system and the Golgi apparatus $[4,5]$. Moreover, several studies have demonstrated that DNM2 directly interacts with the microtubule $[1,6]$ and actin cytoskeleton $[7,8]$. DNM2 is a $98 \mathrm{kDa}$ protein composed of a N-terminal catalytic GTPase domain, a middle domain involved in DNM2 self-assembly, a pleckstrin homology domain $(\mathrm{PH})$ which interacts with membrane phosphatidylinositol 4,5-bisphosphate (PI4,5P2) and therefore is involved in the targeting of dynamin to membranes [9], a GTPase effector domain regulating the GTPase activity, and a C-terminal proline rich domain (PRD) containing multiple Src homology 3 (SH3) binding motifs engaged in protein-protein interactions [10]. Heterozygous mutations in the DNM2 gene cause rare forms of the Charcot-Marie-Tooth peripheral neuropathy (CMT) [11] and autosomal dominant centronuclear myopathy (CNM) [12]. There is no treatment for DNM2related diseases and the pathophysiological mechanisms are still largely unknown.

The focal adhesions (FAs) represent the major site of cell attachment to the extracellular matrix (ECM) where a structural and functional link between the ECM and the intracellular actin cytoskeleton occurs. FAs are macromolecular complexes composed of transmembrane receptors including integrins, structural proteins including vinculin, talin, and $\alpha$-actinin, and signalling proteins such as Focal adhesion kinase (FAK) [13]. FAs act in cell adhesion and migration and dynamics of FA assembly-disassembly is a crucial process to achieve these functions. The molecular mechanisms leading to FA assembly have been well characterized. In contrast, FA disassembly mechanisms are not fully understood. During the last decade, a role of DNM2 in FAs disassembly emerged. The purpose of this review is to summarize the 
studies showing the role of DNM2 as a regulator of FAs dynamics. In addition, we discuss the hypothesis of FA dysfunction in the DNM2-related human diseases.

\section{DNM2-mediated endocytosis at FAs}

The first link between dynamin and components of the FA was reported in 1995 in human monocyte primary cultures stimulated by the macrophage colony-stimulating factor (M-CSF) [14]. Ligand-activated M-CSF receptor recruits a protein complex including dynamin, FAK and the adaptor protein Grb2 (growth factor receptor-bound protein-2). Interestingly, dynamin is phosphorylated and co-immunoprecipitated with activated FAK in M-CSF-treated monocytes suggesting a regulation of dynamin function by FAK that may contribute to receptor internalization. FAK is a non receptor tyrosine kinase involved in the signaling pathway of several agonist-activated membrane receptors including integrins and is mainly expressed at the FA. In addition, FAK is a key element of the regulation of FA disassembly [15] and actin polymerization by phosphorylation of downstream targets [16]. This first demonstration of DNM2 association with FAK had strongly suggested a role for DNM2 at the adhesion sites.

In cultured cells, microtubule depolymerisation by nocodazole results in FA disassembly. After washing the drug, microtubules grow, contact the FAs and lead to FA disassembly [17]. Using this microtubule-induced FA disassembly assay, Ezratty and collaborators showed that disassembly is independent of Rho- and Rac-GTPase activities but dependent on FAKinduced recruitment of DNM2 at the FA via its PRD domain [18]. Before FA disassembly, DNM2 colocalizes with FA and co-immunoprecipitation studies suggest that DNM2 interacts with the phosphorylated, i.e. activated, form of FAK (p-FAK). By the development of a phospho-antibody against DNM2's tyrosine 231, Wang and collaborators further defined the 
DNM2 regulation occurring during FA turnover [19]. The authors showed that activation of Src is responsible for the phosphorylation of DNM2 at the FA where the phosphorylated DNM2 (pDNM2) interacts directly with FAK. Consequently, the formation of a pDNM2FAK-Src complex promotes $\beta 1$-integrin endocytosis and FA disassembly [19]. Such Srcmediated phosphorylation of DNM2 was already shown to induce endocytosis [20]. Inhibition of the DNM2 activity, using dominant negative DNM2-K44E mutant and DNM2-siRNA, inhibits FA disassembly [18] and impairs cell migration [18, 21-23] confirming the central role of DNM2-dependent processes in FA disassembly.

Additional data strongly suggested that clathrin-mediated endocytosis is the main route involved in the DNM2-dependent endocytosis of FA components leading to FA disassembly. A rapid accumulation of clathrin occurs in a microtubule-dependent manner as FAs disappear [21] and clathrin depletion impairs microtubule-induced FA disassembly [21, 22] and cell migration [18, 21-23] as shown for DNM2. Clathrin- and DNM2-mediated endocytosis targets specifically $\beta 1$-integrin engaged in extracellular matrix interaction towards the endosomal recycling pathway [21-23]. Among the clathrin adaptors responsible for clathrin recruitment to endocytic pits, endocytosis of $\beta 1$-integrin at the FA involves either Dab2 (disabled 2) and ARH (autosomal recessive hypercholesterolemia protein) in NIH-3T3 cells [21] or AP2 (adaptor-related protein complex 2) and Dab2 in the HT1080 cell line [22]. These apparent differences suggest a cell-specific combination of clathrin adaptors for integrin endocytosis and FA disassembly. Even if clathrin-mediated endocytosis seems to be the major route for integrin endocytosis leading to FA disassembly, involvement of DNM2- and caveolin-dependent endocytosis was reported [24, 25] suggesting that caveolin-mediated endocytosis may also participate in the FA disassembly. Further studies will be necessary to better define if clathrin- or caveolae-dependent endocytosis pathways could be exploited in a cell-specific manner or if they both coexist in a single cell. 


\section{DNM2 targeting to FAs}

In addition to its interaction with FAK, DNM2 may be targeted to the FA by interacting with syndecan 4 mediated by the PH domain of DNM2 [26]. Syndecan 4 is a heparan sulphate proteoglycan involved in the formation of FAs and actin stress fibres [27, 28]. It regulates FAK activity by increasing FAK phosphorylation in a Rho-dependent manner [29], and participates in integrin internalization [25]. In NIH-3T3 cells treated with lisophosphatidic acid to induce FA formation, DNM2 and syndecan 4 are both recruited and interact at FAs [26]. This study shows that DNM2 is recruited at the FA as soon as FAs are formed and engaged via ECM interaction. Even if syndecan 4 do target DNM2 to FAs, syndecan 4 endocytosis itself occurs via a clathrin- and DNM2-independent process [30] showing a tightly regulated sorting of FA components targeted to the clathrin- and DNM2-associated endocytic vesicles.

DNM2 may also be targeted at FAs by interaction via its $\mathrm{PH}$ domain with the PI4,5P2 enriched at the FA. In fact, local production of this phosphoinositide which also interacts with syndecan 4 [31], may increase recruitment and activation of DNM2 and the endocytic machinery leading to vesicle formation [32]. Interestingly, it was shown that FA disassembly is dependent on the type 1 phosphatidylinositol phosphate kinase beta (PIPK $\beta$ ) located at the FA before disassembly which locally produces the PI4,5P2 allowing recruitment of clathrin, clathrin adaptors (Dab2 and AP2) and DNM2 and formation of the FAK-DNM2 complex [23]. Concerning clathrin and adaptors, the cytoplasmic domain of $\beta$-integrins contains NPXY motif [33] necessary for their recruitment. However, an interesting possibility is that clathrin could be targeted to the FA by interacting with other components of FAs. Indeed, $\alpha$-actinin 
and vinculin, two components of the integrin-based adhesion sites [13], have been shown to interact directly with clathrin heavy chain $[34,35]$.

\section{DNM2-dependent mechanisms in FA regulation}

Processes involved in the turnover of FA components include the microtubule-mediated regulation of FA dynamics $[17,36]$ leading to DNM2-dependent integrins endocytosis as discussed earlier. FA turnover also includes proteolysis by calpains [37, 38] and protein dephosphorylation by phosphatases [39]. The importance of calpain 2, a calcium-dependant protease, was shown for the proteolysis of talin and the subsequent disassembly of the macromolecular complexes also including paxilin and vinculin [37]. More recently, calpain 2mediated proteolysis of FAK was also shown to contribute to the regulation of FA turnover [38]. FAK is composed of a N-terminal FERM domain ( $\mathrm{F}$ for 4.1 protein, $\mathrm{E}$ for ezrin, $\mathrm{R}$ for radixin and $\mathrm{M}$ for moesin), which interacts with DNM2 [19], the catalytic kinase domain containing the binding site for Src and a FAT (focal adhesion targeting) domain involved in the recruitment of FAK to the FA [40]. The cleavage site of FAK by calpain 2 was mapped at the serine residue in position 745 located between the kinase and FAT domains [38]. The consequences of calpain-mediated proteolysis on the FAK-Src-DNM2 complex and on the DNM2-dependent FA disassembly were not investigated until now. It is tempting to speculate that the proteolysis contributes to the activation of the clathrin and DNM2-mediated endocytosis maybe by allowing an increased polymer formation and GTPase activity of DNM2.

Another mechanism of DNM2-dependent regulation of FA emerged from studies performed on podosomes, a transient adhesion site specific to motile cells [41]. In osteoclasts, DNM2 is recruited at podosomes by the activated phosphorylated form of Pyk2; i.e. a focal 
adhesion kinase highly homologous to FAK, which in turn induces a negative feedback loop leading to the dephosphorylation and inactivation of Pyk2 [42]. The DNM2-dependent dephosphorylation of FAK was also reported [42]. Recently, the mechanism of the DNM2dependent Pyk2 dephosphorylation was demonstrated to be mediated by the tyrosine phosphatase PTP-PEST leading to the arrest of Pyk2 downstream signaling [43]. PTP-PEST is known to dephosphorylate several components of FAs [44, 45]. Eleniste and collaborators showed that dynamin's GTPase activity is required for the formation of the DNM-Pyk2-PTP complex [43]. The recruitment of the PTP-PEST phosphatase by DNM2 when its GTPase activity increases may be a more general mechanism at the FAs resulting to the dephosphorylation of FA components, inactivation of signaling cascades, disengagement of integrins and finally FA disassembly. Further studies will be necessary to better define the temporal regulation and coordination of these different processes. For example, it was already demonstrated that calpain is required for microtubule-mediated FA disassembly [46] showing that FA disassembly is an intricately regulated process.

In addition to its role in endocytosis, DNM2 is a well known regulator of the actin network dynamics [47-49]. One can hypothesize a wider function of DNM2 at the FA besides its role in endocytosis of FA components. In particular, interactions of DNM2 with several other proteins need to be further characterized at the FA. DNM2 interacts with Cbl (Casitas Blineage Lymphoma) in podosomes of osteoclasts [50] and with CAP (Cbl-associated protein) [51] involved in remodeling of the actin cytoskeleton at adhesion sites [52, 53] suggesting that DNM2 may also participate in actin network dynamics at the FA before disassembly. It was also shown that the CAP-DNM2 complex negatively regulates receptor-mediated endocytosis [51]. A similar complex may occur at FAs and inhibit DNM2 activity before disassembly signaling occurs. 
Figure 1 summarizes the known interactions of DNM2 with FA components including FAK, PTP-PEST phosphatase and syndecan 4. The available data demonstrate that DNM2 is per se a component of FA and that the endocytic machinery including clathrin adaptors, clathrin, and DNM2 probably start being recruited at the FA during their formation and maturation by interaction with specific FA components. The subsequent clathrin- and DNM2mediated endocytosis of FA components, which recycle back to the plasma membrane [54], allows turnover of FA.

\section{Relevance in DNM2-related human diseases}

Mutations in the DNM2 gene cause rare forms of Charcot-Marie-Tooth peripheral neuropathy (CMT) [11]. Among the hypotheses proposed to explain the CMT pathogenesis, impaired intracellular transport is of particular interest due to the number of CMT genes involved in intracellular trafficking [55]. Given that CMT-related DNM2 mutations impaired clathrin-mediated or clathrin-independent endocytosis $[6,11,56,57]$, a defect in integrin internalization and FA turnover may participate in the pathomechanisms of the disease. In agreement with this hypothesis, CMT-related DNM2 mutants inhibit clathrin-mediated endocytosis in motor neuronal cells and Schwann cells and strongly impaired myelination [58]. In this study, over-expression of the K562E CMT-mutant in rat primary Schwann cells increases the plasma membrane content of $\beta 1$-integrin probably by endocytosis impairment. On the other hand, integrin-based adhesion sites play important roles in the regulation of cell surface receptor, neurotransmitter receptors, and calcium signaling in neurons [59]; several processes potentially impaired by $D N M 2$ mutation.

Mutations in the DNM2 gene also cause autosomal dominant centronuclear myopathy (CNM) [12], a slowly progressive congenital myopathy. The mature skeletal muscle fibres 
have two distinct FA types: the integrin- and the $\beta$-dystroglycan ( $\beta$-DG)-mediated adhesions [60]. The $\beta$-DG is an integral membrane protein included in the dystrophin-associated glycoprotein complex (DGC) which links extracellular laminin and ECM proteins to the intracellular actin cytoskeleton. The two types of FA are concentrated at two specialized adhesives structures of muscle fibres; i.e. the muscle-tendon attachment at myotendinous junctions and the muscle-ECM attachment at costameres along the fibres. Due to muscle intrinsic functional properties, these two adhesives structures have a crucial protective role against contractile damages during contraction and relaxation cycles and are essential for maintaining integrity of sarcomeres; i.e. the contractile unit of the muscle fibres. Several muscular dystrophies are linked to mutations in components of the two FA types [61]. In muscle, integrin-mediated adhesion sites are dynamic structures, crucial for structural integrity [62], which require clathrin-mediated endocytosis for turnover [63]. The first link between CNM and adhesion sites was recently demonstrated in drosophila [64]. MTM1, a phosphoinositide phosphatase mutated in the X-linked recessive form of CNM [65] participates in maintenance of muscle attachment sites through a role in integrin trafficking at myotendinous junctions and FAs [64]. Given that CNM-related DNM2 mutations may impair clathrin-mediated and clathrin-independent endocytosis [56, 57, 66], future studies will be necessary in order to determine if similar impact may be due to DNM2 mutations.

One important question is to understand the tissue-specific impact of DNM2 mutations on skeletal muscle or peripheral nervous system. In cultured neurons, DNM2 interacts with ArgBP2 (Arg and Abl Binding Protein 2) and its brain-specific isoform nArgBP2; two proteins involved in the regulation of actin cytoskeleton at the cell adhesion sites [67]. Interaction of DNM2 with cell type-specific FA components may participate to the tissuespecific impact of DNM2 mutations. Alternatively, one may hypothesize a cell-type specific effect of distinct DNM2 mutants. Indeed, CMT-mutants but not CNM-mutants impair 
endocytosis in peripheral nerve model [58]. Similar comparative studies on FA disassembly using skeletal muscle and peripheral nerve models will be necessary for deciphering the tissue-specific impact of DNM2 mutations.

\section{Conclusions}

Consistent data now exist to show the importance of DNM2 at the cell-matrix adhesion sites. By interacting with syndecan 4 and FAK, DNM2 is per se a component of the focal adhesion sites. DNM2 is probably recruited early during the FA formation process and may regulate actin dynamics. In addition, DNM2 plays a central role in FA disassembly through the link with four disassembly signaling: i) DNM2 is a regulator of the microtubule cytoskeleton, ii) Disassembly is dependent on the activity of the PIPK $\beta$ which locally produces PI4,5P2 which binds DNM2, iii) Calpain-dependent proteolysis acts on FAK which interacts with DNM2, and iv) DNM2 interacts with PTP-PEST, a phosphatase involved in FA disassembly. These data highlight a new promising pathophysiological hypothesis that should be further studied in DNM2-related human diseases. 


\section{Acknowledgements}

This work was supported by the Institut National de la Santé et de la Recherche Médicale (INSERM), the Association Institut de Myologie (AIM), the Université Pierre et Marie CurieParis6 and the Centre National de la Recherche Scientifique (CNRS). LB is recipient of an AIM fellowship.

\section{Disclosure of potential conflict of interest}

There is no conflict of interest to disclose. 


\section{References}

1. Warnock DE, Baba T, Schmid SL (1997) Ubiquitously expressed dynamin-II has a higher intrinsic GTPase activity and a greater propensity for self-assembly than neuronal dynamin-I. Mol Biol Cell 8: 2553-2562

2. Gold ES, Underhill DM, Morrissette NS, Guo J, McNiven MA, Aderem A (1999) Dynamin 2 is required for phagocytosis in macrophages. J Exp Med 190: 1849-1856

3. Henley JR, Krueger EW, Oswald BJ, McNiven MA (1998) Dynamin-mediated internalization of caveolae. J Cell Biol 141: 85-99

4. van Dam EM, Stoorvogel W (2002) Dynamin-dependent transferrin receptor recycling by endosome-derived clathrin-coated vesicles. Mol Biol Cell 13: 169-182

5. Jones SM, Howell KE, Henley JR, Cao H, McNiven MA (1998) Role of dynamin in the formation of transport vesicles from the trans-Golgi network. Science 279: 573-577

6. Tanabe K, Takei K (2009) Dynamic instability of microtubules requires dynamin 2 and is impaired in a Charcot-Marie-Tooth mutant. J Cell Biol 185: 939-948

7. McNiven MA, Kim L, Krueger EW, Orth JD, Cao H, Wong TW (2000) Regulated interactions between dynamin and the actin-binding protein cortactin modulate cell shape. $\mathrm{J}$ Cell Biol 151: 187-198

8. Mooren OL, Kotova TI, Moore AJ, Schafer DA (2009) Dynamin2 GTPase and cortactin remodel actin filaments. J Biol Chem 284: 23995-24005

9. Dong J, Misselwitz R, Welfle H, Westermann P (2000) Expression and purification of dynamin II domains and initial studies on structure and function. Protein Expr Purif 20: 314323

10. Durieux A, Prudhon B, Guicheney P, Bitoun M (2010) Dynamin 2 and Human diseases. J Mol Med 88: 339-350

11. Zuchner S, Noureddine M, Kennerson M, Verhoeven K, Claeys K, De Jonghe P, Merory J, Oliveira SA, Speer MC, Stenger JE, Walizada G, Zhu D, Pericak-Vance MA, Nicholson G, Timmerman V, Vance JM (2005) Mutations in the pleckstrin homology domain of dynamin 2 cause dominant intermediate Charcot-Marie-Tooth disease. Nat Genet 37: 289294

12. Bitoun M, Maugenre S, Jeannet PY, Lacène E, Ferrer X, Laforêt P, Martin JJ, Laporte J, Lochmuller H, Beggs AH, Fardeau M, Eymard B, Romero NB, Guicheney P (2005) Mutations in dynamin 2 cause dominant Centronuclear Myopathy. Nat Genet 37: 1207-1209

13. Kanchanawong P, Shtengel G, Pasapera AM, Ramko EB, Davidson MW, Hess HF, Waterman CM (2010) Nanoscale architecture of integrin-based cell adhesions. Nature 468: 580-584

14. Kharbanda S, Saleem A, Yuan Z, Emoto Y, Prasad KV, Kufe D (1995) Stimulation of human monocytes with macrophage colony-stimulating factor induces a Grb2-mediated association of the focal adhesion kinase pp125FAK and dynamin. Proc Natl Acad Sci U S A 92: 6132-6136

15. Webb DJ, Donais K, Whitmore LA, Thomas SM, Turner CE, Parsons JT, Horwitz AF (2004) FAK-Src signalling through paxillin, ERK and MLCK regulates adhesion disassembly. Nat Cell Biol 6: 154-161

16. Schober M, Raghavan S, Nikolova M, Polak L, Pasolli HA, Beggs HE, Reichardt LF, Fuchs E (2007) Focal adhesion kinase modulates tension signaling to control actin and focal adhesion dynamics. J Cell Biol 176: 667-680

17. Kaverina I, Krylyshkina O, Small JV (1999) Microtubule targeting of substrate contacts promotes their relaxation and dissociation. J Cell Biol 146: 1033-1044 
18. Ezratty EJ, Partridge MA, Gundersen GG (2005) Microtubule-induced focal adhesion disassembly is mediated by dynamin and focal adhesion kinase. Nat Cell Biol 7: 581-590

19. Wang Y, Cao H, Chen J, McNiven MA (2011) A direct interaction between the large GTPase dynamin-2 and FAK regulates focal adhesion dynamics in response to active Src. Mol Biol Cell 22: 1529-1538

20. Cao H, Chen J, Krueger EW, McNiven MA (2010) SRC-mediated phosphorylation of dynamin and cortactin regulates the "constitutive" endocytosis of transferrin. Mol Cell Biol 30: 781-792

21. Ezratty EJ, Bertaux C, Marcantonio EE, Gundersen GG (2009) Clathrin mediates integrin endocytosis for focal adhesion disassembly in migrating cells. J Cell Biol 187: 733747

22. Chao WT, Kunz J (2009) Focal adhesion disassembly requires clathrin-dependent endocytosis of integrins. FEBS Lett 583: 1337-1343

23. Chao WT, Ashcroft F, Daquinag AC, Vadakkan T, Wei Z, Zhang P, Dickinson ME, Kunz J (2010) Type I phosphatidylinositol phosphate kinase beta regulates focal adhesion disassembly by promoting beta1 integrin endocytosis. Mol Cell Biol 30: 4463-4479

24. Vassilieva EV, Gerner-Smidt K, Ivanov AI, Nusrat A (2008) Lipid rafts mediate internalization of beta1-integrin in migrating intestinal epithelial cells. Am J Physiol Gastrointest Liver Physiol 295: G965-976

25. Bass MD, Williamson RC, Nunan RD, Humphries JD, Byron A, Morgan MR, Martin P, Humphries MJ (2011) A syndecan-4 hair trigger initiates wound healing through caveolinand RhoG-regulated integrin endocytosis. Dev Cell 21: 681-693

26. Yoo J, Jeong MJ, Cho HJ, Oh ES, Han MY (2005) Dynamin II interacts with syndecan-4, a regulator of focal adhesion and stress-fiber formation. Biochem Biophys Res Commun 328: 424-431

27. Echtermeyer F, Baciu PC, Saoncella S, Ge Y, Goetinck PF (1999) Syndecan-4 core protein is sufficient for the assembly of focal adhesions and actin stress fibers. J Cell Sci 112: 3433-3441

28. Woods A, Longley RL, Tumova S, Couchman JR (2000) Syndecan-4 binding to the high affinity heparin-binding domain of fibronectin drives focal adhesion formation in fibroblasts. Arch Biochem Biophys 374: 66-72

29. Wilcox-Adelman SA, Denhez F, Goetinck PF (2002) Syndecan-4 modulates focal adhesion kinase phosphorylation. J Biol Chem 277: 32970-32977

30. Tkachenko E, Lutgens E, Stan RV, Simons M (2004) Fibroblast growth factor 2 endocytosis in endothelial cells proceed via syndecan-4-dependent activation of Rac1 and a Cdc42-dependent macropinocytic pathway. J Cell Sci 117: 3189-3199

31. Oh ES, Woods A, Lim ST, Theibert AW, Couchman JR (1998) Syndecan-4 proteoglycan cytoplasmic domain and phosphatidylinositol 4,5-bisphosphate coordinately regulate protein kinase $\mathrm{C}$ activity. J Biol Chem 273: 10624-10629

32. Di Paolo G, De Camilli P (2006) Phosphoinositides in cell regulation and membrane dynamics. Nature 443: 651-657

33. De Deyne PG, O'Neill A, Resneck WG, Dmytrenko GM, Pumplin DW, Bloch RJ (1998) The vitronectin receptor associates with clathrin-coated membrane domains via the cytoplasmic domain of its beta5 subunit. J Cell Sci 111: 2729-2740

34. Merisko EM, Welch JK, Chen TY, Chen M (1988) Alpha-actinin and calmodulin interact with distinct sites on the arms of the clathrin trimer. J Biol Chem 263: 15705-15712

35. Fausser JL, Ungewickell E, Ruch JV, Lesot H (1993) Interaction of vinculin with the clathrin heavy chain. J Biochem 114: 498-503

36. Stehbens S, Wittmann T (2012) Targeting and transport: how microtubules control focal adhesion dynamics. J Cell Biol 198: 481-489 
37. Franco SJ, Rodgers MA, Perrin BJ, Han J, Bennin DA, Critchley DR, Huttenlocher A (2004) Calpain-mediated proteolysis of talin regulates adhesion dynamics. Nat Cell Biol 6: 977-983

38. Chan KT, Bennin DA, Huttenlocher A (2010) Regulation of adhesion dynamics by calpain-mediated proteolysis of focal adhesion kinase (FAK). J Biol Chem 285: 11418-11426

39. Burridge K, Sastry SK, Sallee JL (2006) Regulation of cell adhesion by proteintyrosine phosphatases. I. Cell-matrix adhesion. J Biol Chem 281: 15593-15596

40. Mitra SK, Hanson DA, Schlaepfer DD (2005) Focal adhesion kinase: in command and control of cell motility. Nat Rev Mol Cell Biol 6: 56-68

41. Spinardi L, Marchisio PC (2006) Podosomes as smart regulators of cellular adhesion. Eur J Cell Biol 85: 191-194

42. Bruzzaniti A, Neff L, Sandoval A, Du L, Horne WC, Baron R (2009) Dynamin reduces Pyk2 Y402 phosphorylation and SRC binding in osteoclasts. Mol Cell Biol 29: 36443656

43. Eleniste PP, Du L, Shivanna M, Bruzzaniti A (2012) Dynamin and PTP-PEST cooperatively regulate Pyk2 dephosphorylation in osteoclasts. Int J Biochem Cell Biol 44: 790-800

44. Shen Y, Lyons P, Cooley M, Davidson D, Veillette A, Salgia R, Griffin JD, Schaller MD (2000) The noncatalytic domain of protein-tyrosine phosphatase-PEST targets paxillin for dephosphorylation in vivo. J Biol Chem 275: 1405-1413

45. Angers-Loustau A, Cote JF, Charest A, Dowbenko D, Spencer S, Lasky LA, Tremblay ML (1999) Protein tyrosine phosphatase-PEST regulates focal adhesion disassembly, migration, and cytokinesis in fibroblasts. J Cell Biol 144: 1019-1031

46. Bhatt A, Kaverina I, Otey C, Huttenlocher A (2002) Regulation of focal complex composition and disassembly by the calcium-dependent protease calpain. J Cell Sci 115: 3415-3425

47. Schafer DA, Weed SA, Binns D, Karginov AV, Parsons JT, Cooper JA (2002) Dynamin2 and Cortactin Regulate Actin Assembly and Filament Organization. Current Biology 12: 1852-1857

48. Itoh T, Erdmann KS, Roux A, Habermann B, Werner H, De Camilli P (2005) Dynamin and the actin cytoskeleton cooperatively regulate plasma membrane invagination by BAR and F-BAR proteins. Dev Cell 9: 791-804

49. Lee E, De Camilli P (2002) Dynamin at actin tails. Proc Natl Acad Sci U S A 99: 161166

50. Bruzzaniti A, Neff L, Sanjay A, Horne WC, De Camilli P, Baron R (2005) Dynamin forms a Src kinase-sensitive complex with $\mathrm{Cbl}$ and regulates podosomes and osteoclast activity. Mol Biol Cell 16: 3301-3313

51. Tosoni D, Cestra G (2009) CAP (Cbl associated protein) regulates receptor-mediated endocytosis. FEBS Lett 583: 293-300

52. Sanjay A, Houghton A, Neff L, DiDomenico E, Bardelay C, Antoine E, Levy J, Gailit J, Bowtell D, Horne WC, Baron R (2001) Cbl associates with Pyk2 and Src to regulate Src kinase activity, alpha(v)beta(3) integrin-mediated signaling, cell adhesion, and osteoclast motility. J Cell Biol 152: 181-195

53. Ribon V, Herrera R, Kay BK, Saltiel AR (1998) A role for CAP, a novel, multifunctional Src homology 3 domain-containing protein in formation of actin stress fibers and focal adhesions. J Biol Chem 273: 4073-4080

54. Caswell PT, Norman JC (2006) Integrin trafficking and the control of cell migration. Traffic 7: 14-21

55. Bucci C, Bakke O, Progida C (2012) Charcot-Marie-Tooth disease and intracellular traffic. Prog Neurobiol 99: 191-225 
56. Koutsopoulos OS, Koch C, Tosch V, Bohm J, North KN, Laporte J (2011) Mild functional differences of dynamin 2 mutations associated to centronuclear myopathy and charcot-marie-tooth peripheral neuropathy. PLoS One 6: e27498

57. Liu YW, Lukiyanchuk V, Schmid SL (2011) Common membrane trafficking defects of disease-associated dynamin 2 mutations. Traffic 12: 1620-1633

58. Sidiropoulos PN, Miehe M, Bock T, Tinelli E, Oertli CI, Kuner R, Meijer D, Wollscheid B, Niemann A, Suter U (2012) Dynamin 2 mutations in Charcot-Marie-Tooth neuropathy highlight the importance of clathrin-mediated endocytosis in myelination. Brain 135: $1395-1411$

59. Wu X, Reddy DS (2012) Integrins as receptor targets for neurological disorders. Pharmacol Ther 134: 68-81

60. Ervasti JM (2003) Costameres: the Achilles' heel of Herculean muscle. J Biol Chem 278: $13591-13594$

61. Dalkilic I, Kunkel LM (2003) Muscular dystrophies: genes to pathogenesis. Curr Opin Genet Dev 13: 231-238

62. Perkins AD, Ellis SJ, Asghari P, Shamsian A, Moore ED, Tanentzapf G (2010) Integrin-mediated adhesion maintains sarcomeric integrity. Dev Biol 338: 15-27

63. Yuan L, Fairchild MJ, Perkins AD, Tanentzapf G (2010) Analysis of integrin turnover in fly myotendinous junctions. J Cell Sci 123: 939-946

64. Ribeiro I, Yuan L, Tanentzapf G, Dowling JJ, Kiger A (2011) Phosphoinositide regulation of integrin trafficking required for muscle attachment and maintenance. PLoS Genet 7: e1001295

65. Laporte J, Hu LJ, Kretz C, Mandel JL, Kioschis P, Coy JF, Klauck SM, Poustka A, Dahl N (1996) A gene mutated in X-linked myotubular myopathy defines a new putative tyrosine phosphatase family conserved in yeast. Nat Genet 13: 175-182

66. Bitoun M, Durieux AC, Prudhon B, Bevilacqua JA, Herledan A, Sakanyan V, Urtizberea A, Cartier L, Romero NB, Guicheney P (2009) Dynamin 2 mutations associated with human diseases impair clathrin-mediated receptor endocytosis. Hum Mutat 30: 14191427

67. Cestra G, Toomre D, Chang S, De Camilli P (2005) The Abl/Arg substrate ArgBP $2 / \mathrm{nArgBP} 2$ coordinates the function of multiple regulatory mechanisms converging on the actin cytoskeleton. Proc Natl Acad Sci U S A 102: 1731-1736 


\section{Legends}

Figure 1. Summary of the DNM2 interactions with FA components.

A. Several processes may participate to the recruitment of DNM2 to FA: i) interaction with FAK in a DNM2-FAK-Src complex, ii) interaction with Syndecan 4, iii) interaction with the PTP-PEST phosphatase, and iv) interaction with PI4,5P2 enriched at the FA. Clathrin adaptors and clathrin heavy chain may be also targeted to the mature FA by interacting with integrin heterodimers, vinculin and $\alpha$-actinin. Under disassembly signaling, the calciumdependent proteolysis by calpain cleaves FAK and other FA components. In addition, the production of PI4,5P2 by PIPK $\beta$ may increase DNM2 membrane recruitment. On the other hand, the dephosphorylation of FA components by phosphatases involves the PTP-PEST phosphatase which interacts with DNM2. B. The combination of the four disassembly stimuli (pink boxes in A) activates the clathrin- and DNM2-mediated endocytosis and recycling of FA components. The figure is focused on DNM2-related processes and consequently, additional interactions between FA components have been omitted. 
A

Focal Adhesion

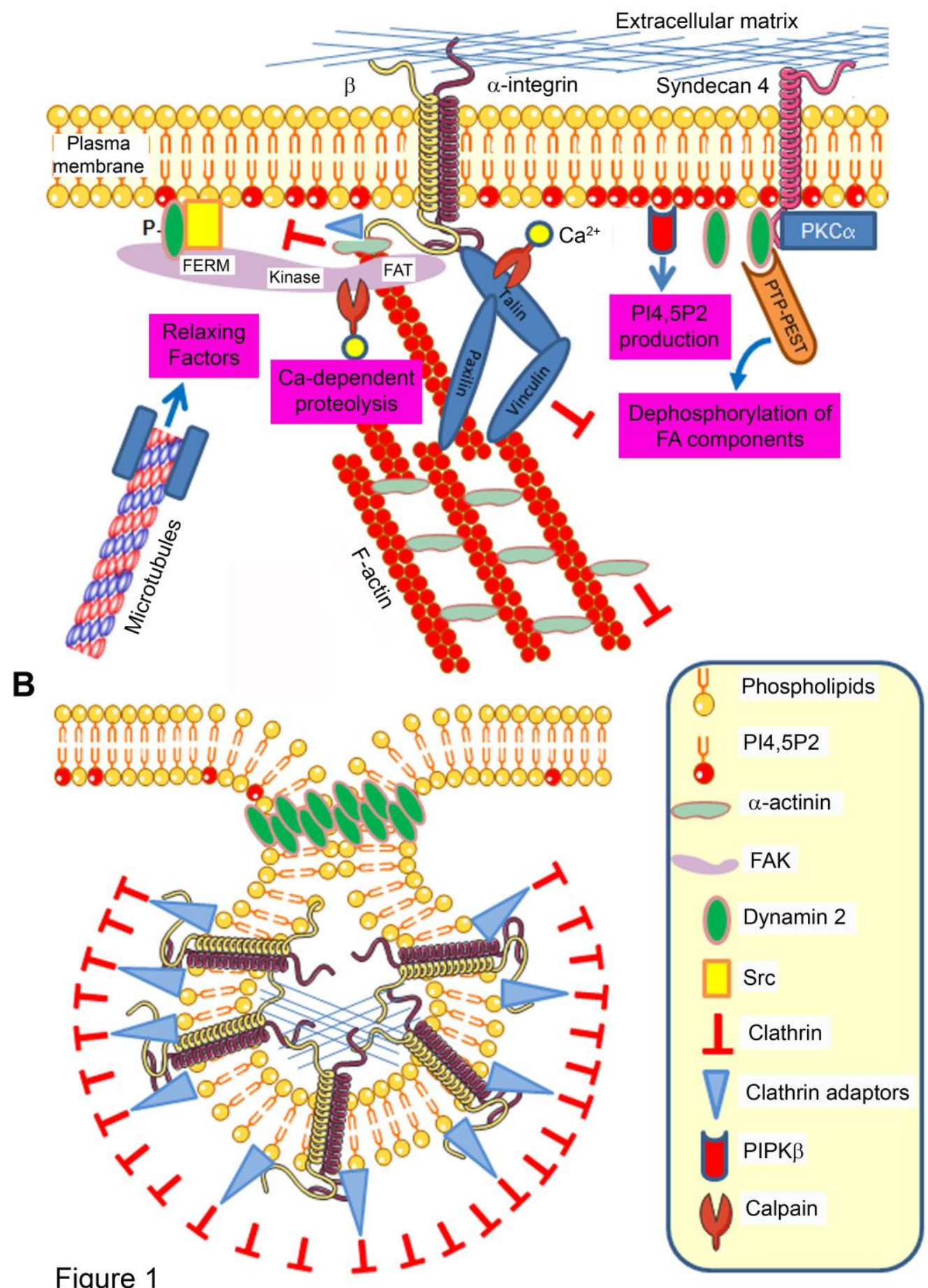

Figure 1 